\title{
Laboratory and clinical Pseudomonas aeruginosa strains do not bind glycosphingolipids in vitro or during type IV pili-mediated initial host cell attachment \\ Correspondence \\ Clifford A. Lingwood \\ cling@sickkids.ca \\ Received 23 January 2006 \\ Revised 19 May 2006 \\ Accepted 1 June 2006

\author{
Aufaugh Emam, ${ }^{1,2}$ Analyn R. Yu, ${ }^{2}$ Hyun-Joo Park, ${ }^{2}$ Radhia Mahfoud, ${ }^{2}$ \\ Julianne Kus, ${ }^{3}$ Lori L. Burrows ${ }^{2,3} \dagger$ and Clifford A. Lingwood ${ }^{1,2,4}$ \\ ${ }^{1}$ Department of Laboratory Medicine and Pathobiology, University of Toronto, Toronto, Ontario, \\ Canada \\ ${ }^{2}$ Research Institute, Hospital for Sick Children, Toronto, Ontario, Canada M5G 1X8 \\ ${ }^{3,4}$ Departments of Surgery ${ }^{3}$ and Biochemistry ${ }^{4}$, University of Toronto, Toronto, Ontario, Canada
}

\section{INTRODUCTION}

Pseudomonas aeruginosa is a Gram-negative bacterium responsible for a variety of opportunistic infections in several clinical settings. Primary among these is lung infection in cystic fibrosis (CF) patients, which is associated with considerable morbidity and mortality (Davies, 2002).

†Present address: Department of Biochemistry and Biomedical Sciences, McMaster University, Rm 4H18 Health Sciences Centre, 1200 Main StW., Hamilton, ON, Canada L8N $3 Z 5$.

Abbreviations: CF, cystic fibrosis; CFTR, cystic fibrosis transmembrane conductance regulator; DAPI, 4',6-diamidino-2-phenylindole dilactate; EHEC, enterohaemorrhagic E. coli; ER, endoplasmic reticulum; FBS, fetal bovine serum; $\mathrm{Gb}_{3}$, globotriaosylceramide; $\mathrm{Gg}_{3}$, gangliotriaosylceramide; $\mathrm{Gg}_{4}$, gangliotetraosylceramide; GSL, glycosphingolipid; HA, haemagglutinin; PIBM, polyisobutylmethacrylate; P4, 1-phenyl-2-palmitoylamino-3-pyrrolidino-1-propanol; RELISA, receptor ELISA; SGC, sulfagalactosylceramide; T4P, type IV pili; wt, wild-type.
P. aeruginosa, together with Burkholderia cepacia, is a principal cause of death of such individuals (Gibson et al., 2003). P. aeruginosa expresses long polar type IV pili (T4P), which are involved in adherence to cells (Irvin et al., 1989) and a variety of artificial materials (Wall \& Kaiser, 1999). The T4P of $P$. aeruginosa have been recently classified into five phylogenetically distinct groups based on amino acid sequence, and presence of accessory genes potentially involved in post-translational modification of the pilins (Kus et al., 2004). The finding that $P$. aeruginosa expressing type IV pili belonging to group 1 are significantly overrepresented among isolates from the CF population (Kus et al., 2004) prompted the current study to determine whether differential receptor binding specificity might explain this epidemiological correlation. The binding of T4P in in vitro assays to the glycosphingolipids (GSLs) gangliotriaosylceramide ( $\mathrm{GalNAc} \beta 1-4 \mathrm{Gal} \beta$ - $4 \mathrm{Glc}$ ceramide, $\mathrm{Gg}_{3}$ ) and gangliotetraosylceramide (Gal $\beta 1-3 \mathrm{GalNAc} \beta 1-4 \mathrm{Gal}$ 
$\beta$-4Glc ceramide, $\mathrm{Gg}_{4}$ ) (also commonly termed asialoGM2 and asialoGM1, respectively) (Comolli et al., 1999b; Gupta et al., 1994; Lee et al., 1994; Saiman \& Prince, 1993; Schweizer et al., 1998) has implicated these molecules as cellular receptors for adhesion of $P$. aeruginosa (Baker et al., 1990; de Bentzmann et al., 1996; Hazlett et al., 1993; Krivan et al., 1988a; Ramphal et al., 1991a). These GSLs contain the common sequence GalNAc $\beta 1-4 \mathrm{Gal}$, which has been defined as the minimal T4P recognition epitope or adhesintope (Campbell et al., 1997; Lee et al., 1996). Receptor ELISA (RELISA) assays based on the binding to this disaccharide sequence have been used to study the mechanism of T4P receptor binding, which is mediated by a C-terminal disulfide loop domain exposed on the terminal pilin subunit. Several studies have implicated these GSLs, particularly $\mathrm{Gg}_{4}$, as the host cell receptor for P. aeruginosa, but much of this work has employed indirect techniques, such as inhibition of binding by anti- $\mathrm{Gg}_{4}$ antibodies (Davies et al., 1999; De Bentzmann et al., 1996; Hazlett et al., 1993; Hobden et al., 1996). Some scepticism has arisen with respect to the role that $\mathrm{Gg}_{4}$ might play as a receptor for $P$. aeruginosa (Schroeder et al., 2001), and the possibility that other molecules (Chen \& Hazlett, 2000; Kirschnek et al., 2005; Wu et al., 1995, 1996), including the CF transmembrane conductance regulator (CFTR) chloride transductor itself (Pier et al., 1997), serve as receptors has been suggested. Anti- $\mathrm{Gg}_{4}$ antibodies have been shown to react directly with the bacterium (Schroeder et al., 2001), providing an alternative explanation for earlier findings. $\mathrm{Gg}_{4}$ has been reported to be increased in cells containing non-functional CFTR (Bryan et al., 1998; De Bentzmann et al., 1996; Saiman \& Prince, 1993) due to reduced sialylation (Poschet et al., 2001), providing an attractive hypothesis for the increased colonization of respiratory epithelium of CF patients.

As a prelude to investigating the potential role of $\mathrm{T} 4 \mathrm{P}$ heterogeneity in clinical pathology, we investigated the glycolipid-binding specificity of laboratory and clinical $P$. aeruginosa strains. In this work, we show that none of the tested $P$. aeruginosa strains specifically bound GSLs, and that selective depletion of GSLs from target respiratory epithelial cells had no effect on $P$. aeruginosa binding. These results demonstrate that GSLs are unlikely to be involved as specific receptors in $P$. aeruginosa host cell attachment. We provide a potential explanation for the results of previous binding studies by demonstration of a distinct difference in the GSL binding of bacteria-attached versus cell-free T4P.

\section{METHODS}

Cell lines and cell culture. IB3-1 (ATCC CRL-2777) is a compound heterozygote cell line containing the $\Delta \mathrm{F} 508$ mutation, and a nonsense mutation, W1282X, with a premature termination signal. The S9 (ATCC CRL 2779) cell line is derived from the IB3-1 cell line, in which the CF phenotype has been corrected by transfection with wild-type (wt) adeno-associated viral CFTR (Virella-Lowell et al., 2004). IB3-1 and S9 cells were maintained in LHC-8 serumfree medium containing glutamine (Biosource), supplemented with
$5 \%$ fetal bovine serum (FBS) and $1 \%$ antibiotics (10000 $\mu$ g streptomycin $\mathrm{ml}^{-1}$ and $10000 \mathrm{IU}$ penicillin; Wisent), and incubated at $37^{\circ} \mathrm{C}$ in $5 \% \mathrm{CO}_{2}$.

BHK cell lines were transfected with a vector expressing the haemagglutinin (HA)-tagged $\Delta$ F508 CFTR mutation, a vector expressing the HA-tagged wt gene encoding CFTR, or the vector alone (Haardt et al., 1999). All BHK cell lines were a generous gift of Dr G. Lukacs, Hospital for Sick Children, Toronto, ON, Canada. BHK $\Delta$ F508, BHK wt CFTR, and mock-transfected BHK cells, were maintained in Dulbecco's modified Eagle's medium/Ham's F12 50/50 mix (DMEM/F12 50/50) (Wisent), supplemented with $5 \%$ FBS, $1 \%$ antibiotics, and $250 \mu \mathrm{g}$ methotrexate $\mathrm{ml}^{-1}$. Under these conditions, $>95 \%$ of the CFTR expressed in BHK wt CFTR cells is the correctly folded mature glycosylated form expressed at the cell surface (Sharma et al., 2004).

Antibodies. Anti- $\mathrm{Gg}_{3}$ is a $\mathrm{mAb}(\mathrm{IgM})$ produced by $2 \mathrm{D} 4$, which is a mouse B cell hybridoma cell line (ATCC TIB-185). Anti-Gg $g_{4}$ is a $\mathrm{mAb}(\mathrm{IgM})$ produced by $\mathrm{SH} 34$, which is also a mouse B-cell hybridoma cell line (ATCC CRL-2405). Rabbit anti-PilA is a polyclonal antibody that was raised against purified $P$. aeruginosa T4P in our laboratory. Mouse anti-CFTR mAb, which recognizes a C-terminal epitope in the region of residues 1370-1380, was purchased from Chemicon. Alexa 488 goat anti-mouse IgG antibodies, Alexa 488 goat anti-rabbit IgG, FITC-conjugated goat anti-mouse IgM and DAPI (4',6-diamidino-2-phenylindole dilactate) were purchased from Molecular Probes. TRITC-conjugated goat anti-rabbit IgG, and alkaline-phosphatase-conjugated goat anti-rabbit antibody, were purchased from Sigma-Aldrich. Horseradish-peroxidase-conjugated goat anti-mouse antibody was from Bio-Rad.

P4-mediated depletion of GSLs. P4 (1-phenyl-2-palmitoylamino-3-pyrrolidino-1-propanol; Lee et al., 1999) was a generous gift from Dr J. Shayman, University of Michigan. IB3-1 and S9 cells were maintained for $>10$ days in a medium containing $1 \mu \mathrm{M} \mathrm{P} 4$ reconstituted in DMSO. BHK $\triangle$ F508 and BHK wt CFTR were grown in $2 \mu \mathrm{M} \mathrm{P} 4$.

Bacterial strains. P. aeruginosa strains (PAO1, PAK, PAKnp, PAKpilT, PAKpila, PA103, PAKFliC, HSCPs1, PA14, 1244, PA13, 1457, 1123, 5196 and C27330) were maintained as glycerol stocks at $-80^{\circ} \mathrm{C}$, and were grown on Luria-Bertani (LB) agar plates, or Pseudomonas isolation agar plates, overnight at $37^{\circ} \mathrm{C}$. Cells were removed with a sterile toothpick, and resuspended in RPMI supplemented with $5 \% \mathrm{FBS}$ and $25 \mu \mathrm{M}$ HEPES buffer to an $\mathrm{OD}_{600}$ of $0 \cdot 05$ (equivalent to approx. $5 \times 10^{5}$ cells, as determined by plate counts). Enterohaemorrhagic Escherichia coli (EHEC) CL56 was maintained in LB.

Host cell lipid extraction and saponification. Approximately $10^{7}$ cells were shaken vigorously overnight in $15 \mathrm{ml} \mathrm{2:1}$ chloroform: methanol $(\mathrm{C}: \mathrm{M})$ mixture in a glass tube. The mixture was filtered, and the collected lipids were dried, and resuspended in $2: 1$ $\mathrm{C}: \mathrm{M}$ to give an equivalent of $5 \times 10^{6}$ cells in $20 \mathrm{ml} \mathrm{C}: \mathrm{M}$. Total cellular lipid extract was saponified to isolate the glycolipid fraction. The lipid residue was resuspended in $1 \mathrm{M} \mathrm{NaOH}$ in methanol for $2 \mathrm{~h}$ at $37^{\circ} \mathrm{C}$. The mixture was neutralized with $2 \mathrm{M}$ acetic acid. A small volume of water was added, and the mixture applied onto a C-18 column (Sep-Pak Plus C-18; Waters). The column was washed with water, and glycolipids were eluted with methanol, dried under a stream of nitrogen gas, and resuspended in $2: 1 \mathrm{C}: \mathrm{M}$ to the desired concentration.

Assay of GSL binding by TLC overlay with radiolabelled bacteria. Binding of P. aeruginosa to $\mathrm{Gg}_{3}$ and $\mathrm{Gg}_{4}$, and other GSLs, was assayed by the TLC overlay procedure described by Krivan et al. (1988a), with minor changes. Bacteria were metabolically radiolabelled with $\left[{ }^{35}\right.$ S $]$ methionine [Amersham; $1 \mu \mathrm{Ci} \mathrm{ml}^{-1}\left(1 \mathrm{kBq} \mathrm{ml}{ }^{-1}\right)$ in Davis minimal medium (DMM)] for $22 \mathrm{~h}$ at $37^{\circ} \mathrm{C}$, with no shaking. Viability of greater than $95 \%$ (as determined by viable plate 
counts) was maintained. $\mathrm{Gg}_{3}$ and $\mathrm{Gg}_{4}(2 \mu \mathrm{g}$ of each) were applied to aluminium-backed silica gel plates (Alugram Sil G/UV 254). Total saponified lipid extracts from approximately $7 \times 10^{5}$ IB3-1 and S9 cells were similarly applied to TLC plates. Plates were first precleared in chloroform and methanol in the ratio $98: 2$, followed by application of the GSLs, and separation in chloroform, methanol and water, in a 60:40:9 ratio. One of the plates was stained with orcinol colour reagent (Sigma), and incubated at $110^{\circ} \mathrm{C}$ for $10 \mathrm{~min}$. The remaining plates were air-dried, and dipped in a solution of $0.3 \%$ polyisobutylmethacrylate (PIBM; Aldrich) in acetone for $1 \mathrm{~min}$. PIBM treatment is widely used to enhance ligand binding, but we have found this step to be unnecessary (Yiu \& Lingwood, 1992). Preliminary studies showed that PIBM reduced E. coli CL56 GSL binding, and, therefore, it was omitted for this organism. The GSL binding of Pseudomonas strains was not affected by PIBM pretreatment. The TLC plates were then dried, and blocked with $2 \%$ BSA in $100 \mathrm{mM}$ tricine-buffered saline (TBS) for $2 \mathrm{~h}$ at $37^{\circ} \mathrm{C}$. Log phase ${ }^{35} \mathrm{~S}$-labelled bacteria $\left(1 \times 10^{4}\right.$ c.p.m. $\left.\mathrm{ml}^{-1}\right)$ were resuspended in $100 \mathrm{mM}$ TBS at a concentration of approximately $10^{8} \mathrm{ml}^{-1}$. Plates were covered with the suspension of radiolabelled bacteria for $4 \mathrm{~h}$ at $37^{\circ} \mathrm{C}$, with slow shaking (20 r.p.m.). Unbound bacteria were washed off, and the plates were dried completely before being exposed to a phosphor screen (Molecular Dynamics) for 6 days.

Solid-phase GSL-binding assay (RELISA). Glycolipids were serially diluted in $50 \mu \mathrm{l}$ methanol in the wells of flat-bottomed polystyrene plates (Evergreen Scientific). Plates were left to dry overnight at $4{ }^{\circ} \mathrm{C}$. The wells were blocked with $50 \mu \mathrm{l} 2 \%$ BSA in TBS for $1 \mathrm{~h}$ at $37^{\circ} \mathrm{C}$, after which they were washed five times with TBS. A $50 \mu \mathrm{l}$ volume of $P$. aeruginosa culture (in stationary phase, and taken from agar plates), containing approximately $10^{9}$ bacteria $\mathrm{ml}^{-1}$ in TBS, was added to each well. The plates were covered with Parafilm, and incubated at $37^{\circ} \mathrm{C}$ for $2 \mathrm{~h}$, with slow shaking (20 r.p.m.). Unbound bacteria were washed off with TBS. A polyclonal antibody against the pilin was used to monitor the binding of $P$. aeruginosa to glycolipids. Wells were filled with $50 \mu \mathrm{l}$ of a 1/1000 dilution of this antibody, overnight at $4{ }^{\circ} \mathrm{C}$. This was followed by incubation with $50 \mu \mathrm{l}$ of a 1/2000 dilution of goat anti-rabbit alkaline phosphatase secondary antibody (peroxidase-conjugated antibodies cannot be used with catalase-positive $P$. aeruginosa) for $1 \mathrm{~h}$ at room temperature. Unbound secondary antibody was washed off, and $50 \mu \mathrm{l} \mathrm{mg}$ phosphatase substrate $\mathrm{ml}^{-1}$ in $1 \mathrm{M}$ diethanolamine buffer $(0.5 \mathrm{mM}$ $\mathrm{MgCl}_{2}, \mathrm{pH} 9 \cdot 8$ ) (Sigma) was added to each well. After $30 \mathrm{~min}$ incubation at room temperature, absorbance readings were recorded at $405 \mathrm{~nm}$. CL56 was detected with an anti-whole-cell CL56 mAb, followed by a goat anti-mouse secondary antibody conjugated to horseradish peroxidase.

Bacterial-host-cell adhesion assay. IB3-1 and S9 cells, or BHK cell lines, were seeded onto $18 \mathrm{~mm}$ tissue-culture-treated glass coverslips (Fisher), and grown overnight at $37^{\circ} \mathrm{C}, 5 \% \mathrm{CO}_{2}$, to $70-80 \%$ confluency. The monolayers were washed three times with PBS. $P$. aeruginosa strains were grown overnight on LB agar plates, and resuspended in RPMI 1640 supplemented with HEPES, to give approximately $5 \times 10^{5}$ cells added per coverslip. The coverslips were then incubated at room temperature for $5 \mathrm{~min}$ to allow bacterial adherence to cells. The cells were then washed three times with PBS to remove unbound bacteria, and fixed with $4 \%$ paraformaldehyde for $30 \mathrm{~min}$ on ice, then washed twice with PBS. P. aeruginosa can attach non-specifically to many inert surfaces, and the conditions used in our binding assay were selected, since preliminary studies established significant preferential cell attachment, and no Pseudomonas adhesion to the coverslip alone was detected. Longer incubation resulted in loss of target cell integrity, and significant substrate detachment. In addition, the attachment conditions, as defined, restricted the assay to T4P-mediated attachment, since under these conditions no cell attachment was observed for the T4P-deleted mutant organism. Pseudomonas cell binding increased with time (5-30 $\mathrm{min})$, but not temperature (room temperature versus $37^{\circ} \mathrm{C}$ ) (not shown).

The cells were then permeabilized with $0 \cdot 1 \%$ Triton X-100 for 20 min, and blocked with $1 \%$ BSA for $1 \mathrm{~h}$ at room temperature. Rabbit antiPilA antiserum was used at 1:500 dilution in 1\% BSA to detect bacterial pilin. Any cell binding of the T4P-deficient strain PAKnp (and PAK control) was detected using a mouse anti-O6 LPS mAb (from Dr J. Lam, University of Guelph, Guelph, ON, Canada). The effect of preincubation of PAK and PAKpilT with $0.5 \%$ BSA or $0.5 \%$ gelatin (30 min at room temperature) on S9 cell binding was also compared.

Coverslips were incubated with primary antibody on ice for $1 \mathrm{~h}$, or at $4{ }^{\circ} \mathrm{C}$ overnight. The cells were then washed twice with PBS, followed by addition of the secondary antibody Alexa 488 goat anti-rabbit (or anti mouse) IgG, used at 1:500 dilution in 1\% BSA. The cells were also stained with rhodamine-phalloidin (also a $1: 500$ dilution in 1\% BSA), and incubated for $1 \mathrm{~h}$ on ice, along with the secondary antibody. The cells were then washed with PBS, and the coverslips were mounted on glass slides using DakoCytomation fluorescent mounting medium.

Glycolipid and CFTR immunofluorescence staining. IB3-1 and S9 cells, or BHK cell lines, were seeded onto $18 \mathrm{~mm}$ tissue-culturetreated glass coverslips (Fisher), and grown overnight at $37^{\circ} \mathrm{C}, 5 \%$ $\mathrm{CO}_{2}$, to $70-80 \%$ confluency. The monolayers were then washed three times with PBS, and fixed with $4 \%$ paraformaldehyde for 30 min on ice, and washed twice with PBS. The cells were then permeabilized with $0 \cdot 1 \%$ Triton X-100 for 20 min (except for assays staining for surface glycolipid expression of cells), then blocked with $1 \%$ BSA for $1 \mathrm{~h}$ at room temperature. The appropriate primary antibody - anti-Gg $g_{4}(1: 2)$, anti-Gg $g_{3}(1: 10)$ or anti-CFTR $(1: 500)$ was diluted in $1 \%$ BSA using the appropriate dilution, and incubated for $1 \mathrm{~h}$ or overnight at $4{ }^{\circ} \mathrm{C}$. The cells were then washed three times with PBS, followed by the addition of secondary antibody FITC-conjugated goat anti-mouse IgM (for anti-Gg $\mathrm{Gg}_{4}$ or anti- $\mathrm{Gg}_{3}$ detection) or Alexa 488 goat anti-mouse IgG (for anti-CFTR) - and rhodamine-phalloidin (again, only for cells that had been permeabilized) at 1:500 dilution in 1\% BSA. The cells were incubated for $1 \mathrm{~h}$ on ice, and washed three times with PBS. The coverslips were then mounted on glass slides using DakoCytomation fluorescent mounting medium.

Bacterial adherence and glycolipid fluorescent co-staining. The bacterial adherence assay was performed as described above. The rabbit anti-PilA antibody was used at 1:500 dilution in 1\% BSA to detect bacteria, while $\mathrm{mAb}$ anti- $\mathrm{Gg}_{4}$ was diluted $1: 2$ in $1 \%$ BSA. The fixed bacteria-bound cells were incubated with primary antibodies on ice for $1 \mathrm{~h}$, or at $4{ }^{\circ} \mathrm{C}$ overnight. The cells were then washed three times with PBS, followed by addition of the secondary antibody, which was either TRITC-conjugated goat anti-rabbit IgG used at 1:500 dilution in 1\% BSA, or FITC-conjugated goat antimouse IgM, also at 1:500 dilution in 1\% BSA. The cells were incubated for $1 \mathrm{~h}$ on ice, and washed three times with PBS. The cells were also stained with DAPI at 1:50 in PBS, and incubated for $10 \mathrm{~min}$. The cells were then washed with PBS, and the coverslips were mounted on glass slides using DakoCytomation fluorescent mounting medium.

Fluorescent images were taken using a Zeiss LSM 510 confocal microscope under a $\times 63$ oil-immersion objective. The images were recorded in LSM 510 Meta, and composites were prepared using Adobe Photoshop 7.0.

Preparation of cell-free pili. $P$. aeruginosa was streaked in grid pattern on DMM agar plates containing glucose, and grown overnight. The cells were scraped off the plates, resuspended in PBS, and 
depiliated by vortexing for $1 \mathrm{~min}$. Cells were separated from the supernatant by centrifugation for $30 \mathrm{~min}$ at $15000 \mathrm{~g}$. The supernatant was made $0 \cdot 1 \mathrm{M}$ with respect to $\mathrm{MgCl}_{2}$, and incubated at $4{ }^{\circ} \mathrm{C}$ overnight. The resulting precipitate, which contained the pili, was harvested by centrifugation at $15000 \mathrm{~g}$ for $30 \mathrm{~min}$ at $4{ }^{\circ} \mathrm{C}$.

\section{RESULTS}

\section{GSL content of target eukaryotic cells}

The human CF respiratory epithelium cell line IB3-1, and the corresponding S9 cell line reconstituted with a wt gene encoding CFTR, have been used to assess the interaction between $P$. aeruginosa and host cells (Virella-Lowell et al., 2004). However, the glycolipid content of these cells has not previously been characterized. Fig. 1 shows TLC analysis of the GSL content of these two cell lines. The overall GSL composition (Fig. 1A) of the cells was very similar. $\mathrm{Gg}_{3}$ and $\mathrm{Gg}_{4}$ have been implicated as $P$. aeruginosa host cell receptors, and it has been suggested that these receptors are upregulated in CFTR mutant epithelial cells (De Bentzmann et al., 1996). Using anti- $\mathrm{Gg}_{3}$ and anti-Gg TLC immunostaining, both IB3-1 and S9 cell lines were found to contain very little $\mathrm{Gg}_{3}$. Anti- $\mathrm{Gg}_{4}$ recognized a faster migrating species (comigrating with $\mathrm{Gg}_{3}$ ), in addition to $\mathrm{Gg}_{4}$, in both extracts; both species were elevated approximately twofold in IB3-1 cells. In order to later test for the importance of GSLs in P. aeruginosa host cell binding, the GSL extracts from cells treated with P4, an inhibitor of glucosylceramide synthase (Lee et al., 1999), which therefore prevents the synthesis of most GSLs, were also tested. Both the anti- $\mathrm{Gg}_{4}$ and the weak anti- $\mathrm{Gg}_{3}$ staining were missing in the extract of P4-treated cells (Fig. 1C). Mock-transfected BHK cells, and BHK cells transfected with wt or $\Delta \mathrm{F} 508$ CFTR, were also tested for $\mathrm{Gg}_{3}$ and $\mathrm{Gg}_{4}$ expression, but none expressed detectable levels of either GSL (not shown).

\section{P. aeruginosa-GSL binding in vitro}

The neutral GSL extracts from S9 and IB3-1 cells were used, together with GSL standards, including $\mathrm{Gg}_{3}$ and $\mathrm{Gg}_{4}$, to screen for the potential GSL binding by laboratory and clinical $P$. aeruginosa isolates. Bacteria were metabolically labelled with $\left[{ }^{35} \mathrm{~S}\right]$ methionine, following overnight growth in DMM. After incubation with exponential-phase bacteria, the plates were washed, and autoradiography was used to detect any bound organisms. The autoradiograms were uniformly negative for all $P$. aeruginosa strains tested (Fig. 2). Omission of PIBM treatment of the plate (used to optimize GSL presentation for ligand binding; Yiu \& Lingwood, 1992) made no difference to the results (not shown). Some non-specific binding at the TLC solvent front was seen, but no binding to the GSL fraction, including the $\mathrm{Gg}_{3}$ and $\mathrm{Gg}_{4}$ glycolipid standards, was observed. In contrast, the control EHEC strain CL56, previously demonstrated to show $\mathrm{Gg}_{3}$ and $\mathrm{Gg}_{4}$ binding (Barnett-Foster et al., 1999), adhered to these GSLs (both the standards and within the cell extracts, Fig. 2B) under the same conditions used for P. aeruginosa. Of note is the fact that CL56 binding to $\mathrm{Gg}_{4}$ was more apparent in the IB3-1 than the S9 cell extract. Similarly, CL56 binding to $\mathrm{Gg}_{4}$ and $\mathrm{Gg}_{3}$ was demonstrated by RELISA, but no significant binding for a selection of the $P$. aeruginosa strains was observed in this assay (Fig. 3 ). It has been reported that BSA inhibits $P$. aeruginosa-GSL binding by an unknown mechanism (Ramphal et al., 1991a). We found that use of gelatin as an alternative blocker did not increase $P$. aeruginosa-GSL binding (Fig. 3). Also, preincubation of bacteria with BSA had no effect on $P$. aeruginosa-cell binding (see below).

\section{Host cell GSL depletion}

If binding to $\mathrm{Gg}_{3}$ and $\mathrm{Gg}_{4}$ does play a role in Pseudomonas host cell attachment, and our TLC overlay and RELISA assays were of insufficient sensitivity for detection, depletion of the host cell GSL content should reduce Pseudomonas host cell binding. TLC staining of GSLs with anti-Gg and anti- $\mathrm{Gg}_{3}$ was eliminated following cell treatment with $\mathrm{P} 4$ (Fig. 1). Similarly, cell staining with anti- $\mathrm{Gg}_{3}$ and anti- $\mathrm{Gg}_{4}$ was lost after growth in P4 (Fig. 4). In contrast, antisulfagalactosylceramide (SGC) staining was retained
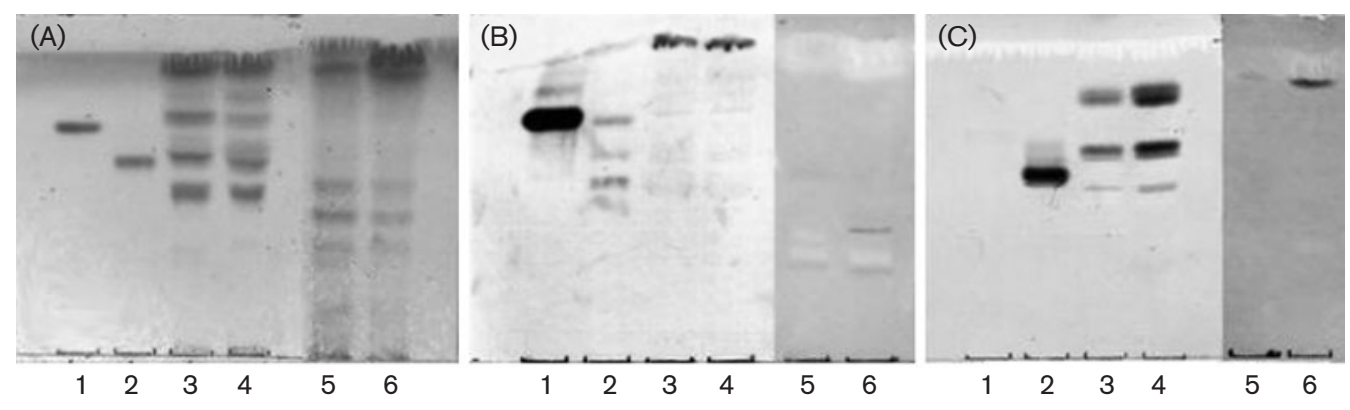

Fig. 1. GSLs of $S 9$ and IB3-1 human lung epithelial cell lines grown with and without P4. (A) Orcinol chemical detection of GSLs, (B) immunodetection of $\mathrm{Gg}_{3}$, and (C) immunodetection of $\mathrm{Gg}_{4}$. Lanes: 1, standard $\mathrm{Gg}_{3}(1 \mu \mathrm{g}) ; 2$, standard $\mathrm{Gg} 4$ $(1 \mu \mathrm{g}) ; 3$ and 5, saponified GSL extract from S9 cells; 4 and 6, saponified GSL extract from IB3-1 cells. Lanes: 3 and 4 , untreated cells; 5 and 6, P4-treated cells. Densitometry showed a 1.9-fold increase in $\mathrm{Gg}_{4}$ in IB3-1 versus S9 cells. 

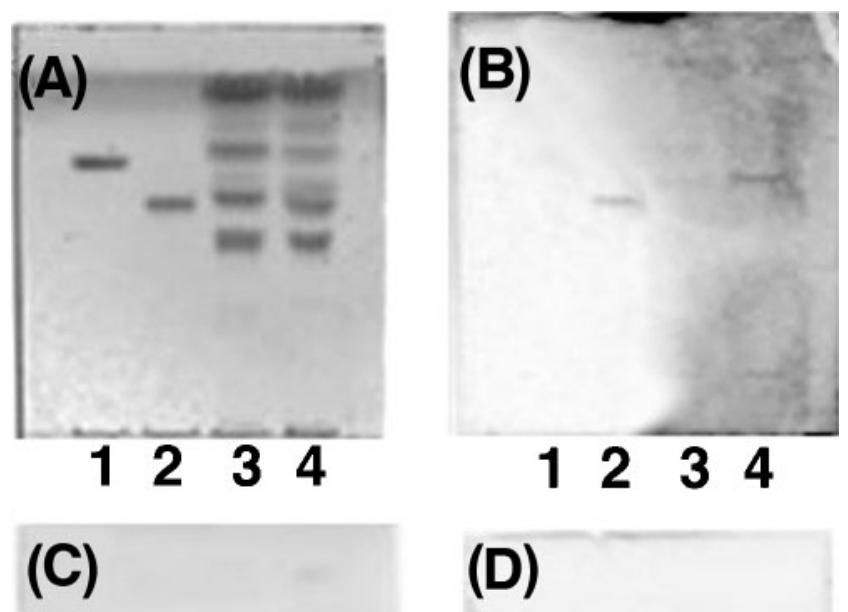

$\begin{array}{llll}1 & 2 & 3 & 4\end{array}$

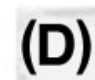

Fig. 2. Assessment of $P$. aeruginosa GSL binding by TLC overlay. Clinical and laboratory strains were metabolically radiolabelled, and binding to GSL standards, and GSL extracts from IB3-1 and S9 cells, was determined by overlay of TLCseparated GSLs. The GSL binding of EHEC strain CL56 was assayed in a similar way. (A) Orcinol stain, (B) EHEC strain CL56, (C) P. aeruginosa strain 1123, (D) P. aeruginosa strain PA103. Strains PAK, PAKFliC, PAO1, PAKpilA, 1244, 5196, 1457, PA14, PA13, HSCPs1, C27330 and C1841 were also tested, and showed no GSL binding. Lanes 1-4 are as in Fig. 1.

(Fig. 4G, H). SGC is a GSL derived from galactosylceramide, and therefore not susceptible to P4 inhibition. Anti- $\mathrm{Gg}_{4}$ staining of IB3-1 and S9 cells was significantly different. $\mathrm{Gg}_{4}$ was only expressed on the surface of IB3-1 cells (Fig. 4B versus $\mathrm{F}$ ) in punctate domains, consistent with lipid rafts. Only when cells were permeabilized could $\mathrm{Gg}_{4}$ be detected in S9 cells. Both intracellular and cell-surface anti- $\mathrm{Gg}_{4}$ staining were eliminated after P4 treatment. Anti-Gg 3 cell staining was not above background levels (not shown).

\section{Effect of host cell GSL depletion on $P$. aeruginosa attachment}

Pseudomonas binding to intact cultured epithelial cells was assessed using a double-fluorescence-labelling procedure in which rhodamine-phalloidin was used to stain actin fibres within host cells, and a rabbit anti-pilin polyclonal antibody was used to detect bound bacteria via the use of an FITCconjugated secondary antibody. In these assays, a clear association of Pseudomonas with both IB3-1 and S9 cells could be seen, but we observed no preferential binding of Pseudomonas to either host cell type (Fig. 5A versus C). In addition, the effect of $\mathrm{P} 4$ depletion of GSLs on P. aeruginosa binding to IB3-1 and S9 cells was not significant (Fig. 5A, C versus $B, D$ ), indicating that $\mathrm{Gg}_{3}$ and $\mathrm{Gg}_{4}$, or indeed any other glucosyl ceramide-based GSLs, do not play a role in the host cell attachment of these organisms. Double labelling of cell-bound organisms and antiGg ${ }_{4}$ (Fig 5E, F) clearly shows that $P$. aeruginosa bound to membrane regions devoid of $\mathrm{Gg}_{4}$. No cell binding of a T4P-deleted $P$. aeruginosa mutant strain was seen (Fig. $5 \mathrm{G}$ versus $\mathrm{H}$ ). Preincubation of bacteria with BSA or gelatin had no effect on cell binding (not shown). Pseudomonas host cell binding is not intimate, and frequently comprises a network of T4P tip-to-tip interactions. These networks are seen for hostcell-bound, but not for the infrequent substrate-bound, organisms.

T4P are retractable, and it was therefore considered possible that GSL recognition could be transient, and perhaps not detected in our TLC overlay experiments. In order to amplify any potential receptor role for GSLs, we tested the effect of $\mathrm{P} 4$ on the cell binding of a pilT mutant of $P$. aeruginosa. This mutant is hyperpiliated, and unable to retract its pili (Chiang \& Burrows, 2003). The multipiliated nature of this mutant can be clearly seen in host-cellattached bacteria (Fig. 6). As reported by Comolli et al. (1999a), this strain bound host cells less effectively than the wt organism, and the extensive interbacterial attachment was not evident; however, P4 GSL depletion did not affect the host cell binding of this strain.

\section{Effect of CFTR overexpression on $\boldsymbol{P}$. aeruginosa attachment}

CFTR itself has been implicated as a receptor for $P$. aeruginosa (Pier et al., 1997). We therefore examined the binding of $P$. aeruginosa to BHK cells stably transfected with wt or $\triangle$ F508 CFTR tagged with HA (Haardt et al., 1999). These cells do not make $\mathrm{Gg}_{3}$ or $\mathrm{Gg}_{4}$ (not shown). The location of CFTR in these transfectants was confirmed by anti-HA staining. Surface expression of CFTR was only evident for wt BHKcells. $\triangle$ F508 CFTR is not at the cell surface, but found intracellularly, consistent with endoplasmic reticulum (ER) accumulation (Haardt et al., 1999). No difference between the binding to wt-CFTR- or $\triangle$ F508-CFTR-transfected BHK cells was seen (Fig. 7A versus B). P4-mediated GSL depletion was similarly without effect on $P$. aeruginosa BHK cell binding (not shown). As for S9 and IB3-1 cells, T4P-mediated networks of non-intimately bound bacteria were present.

\section{GSL binding of cell-free T4P}

Several studies have investigated the $\mathrm{Gg}_{3}$ and $\mathrm{Gg}_{4}$ binding of isolated $P$. aeruginosa T4P, rather than the binding of whole bacteria. We used the RELISA assay to examine the GSL binding of T4P sheared from the PAK strain of P. aeruginosa. 

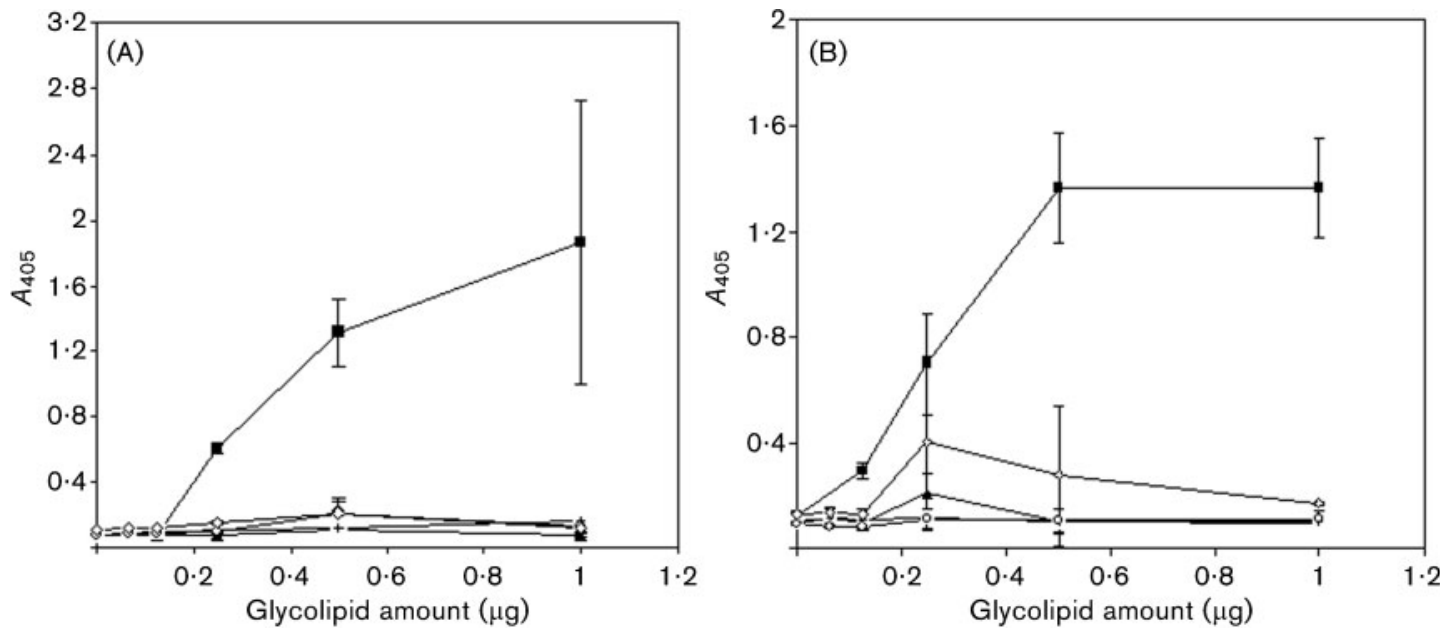

Fig. 3. Comparison of EHEC and $P$. aeruginosa GSL binding by RELISA. Bacterial binding to $\mathrm{Gg}_{4}(\mathrm{~A})$ and $\mathrm{Gg} \mathrm{g}_{3}(\mathrm{~B})$ immobilized in microtitre plates was measured. P. aeruginosa strains: PAK $(\mathbf{\Lambda})$, PAKpilA $(+)$, PAKpilT $(\bigcirc)$, C27330 $(\diamond)$. EHEC strain CL56 ( $\boldsymbol{\square})$ was used as positive control. PAK binding to $\mathrm{Gg}_{3}$ was also tested using bovine skin gelatin as a blocking agent $(\triangle)$. Binding was monitored using a rabbit polyclonal anti-PilA antibody. Error bars show SD.
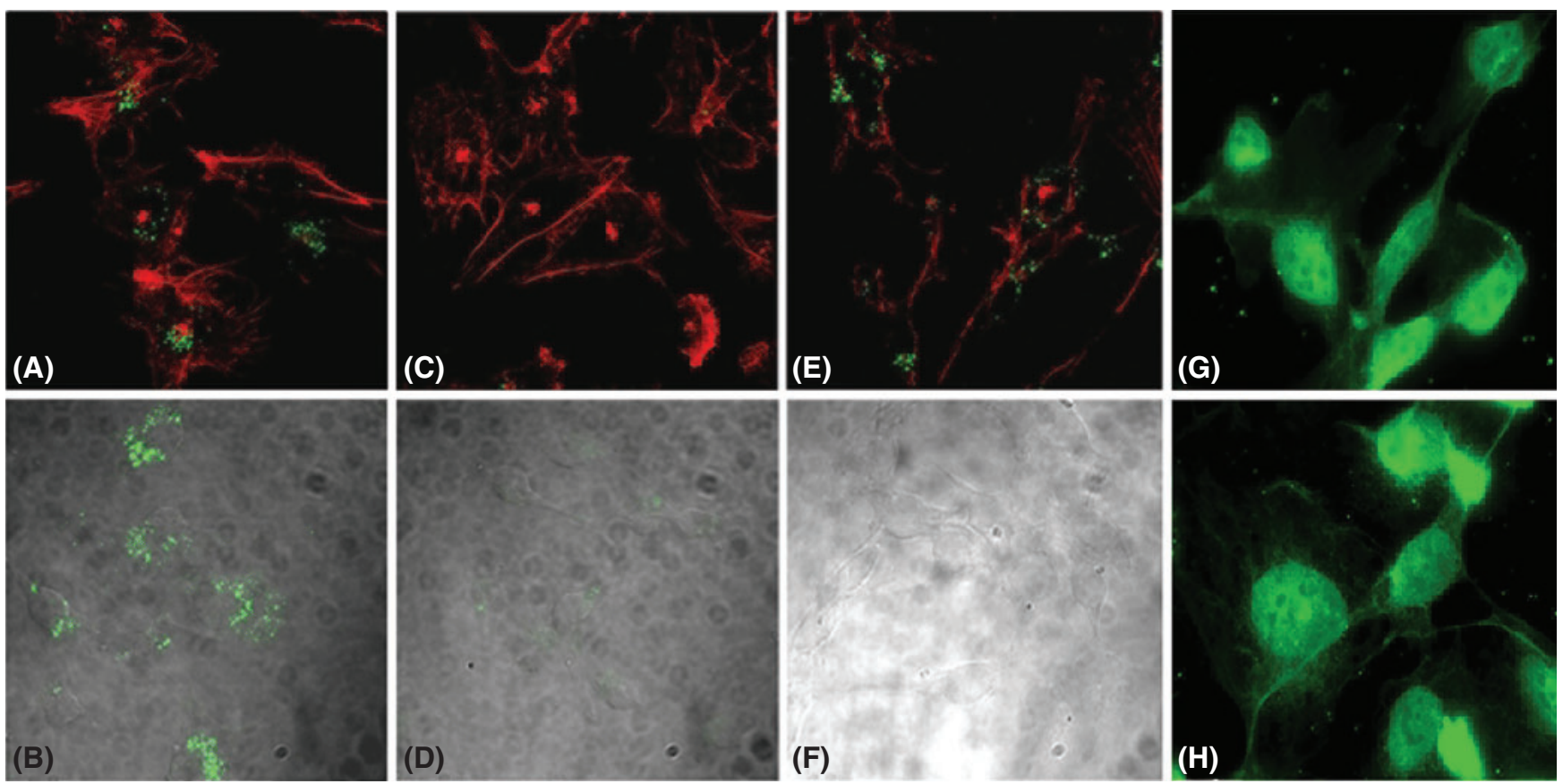

Fig. 4. Effect of $P 4$ on anti-GSL cell staining. (A) Permeabilized untreated IB3-1 cells, with anti-Gg 4 staining; (B) nonpermeabilized untreated IB3-1 cells, with anti-Gg 4 staining, overlaid on a phase-contrast image; (C) permeabilized P4-treated IB3-1 cells, with anti-Gg ${ }_{4}$ staining; (D) non-permeabilized P4-treated IB3-1 cells, with anti-Gg I $_{4}$ staining, overlaid on a phasecontrast image; (E) permeabilized untreated S9 cells, with anti-Gg $\mathrm{G}_{4}$ staining; $(\mathrm{F})$ non-permeabilized untreated S9 cells, with anti-Gg $\mathrm{g}_{4}$ staining, overlaid on a phase-contrast image; $(\mathrm{G})$ permeabilized untreated S9 cells, with anti-SGC staining; $(\mathrm{H})$ permeabilized P4-treated S9 cells, with anti-SGC staining. Permeabilized S9 and IB3-1 cells showed no staining with anti$\mathrm{Gg}_{3}$ (not shown). 

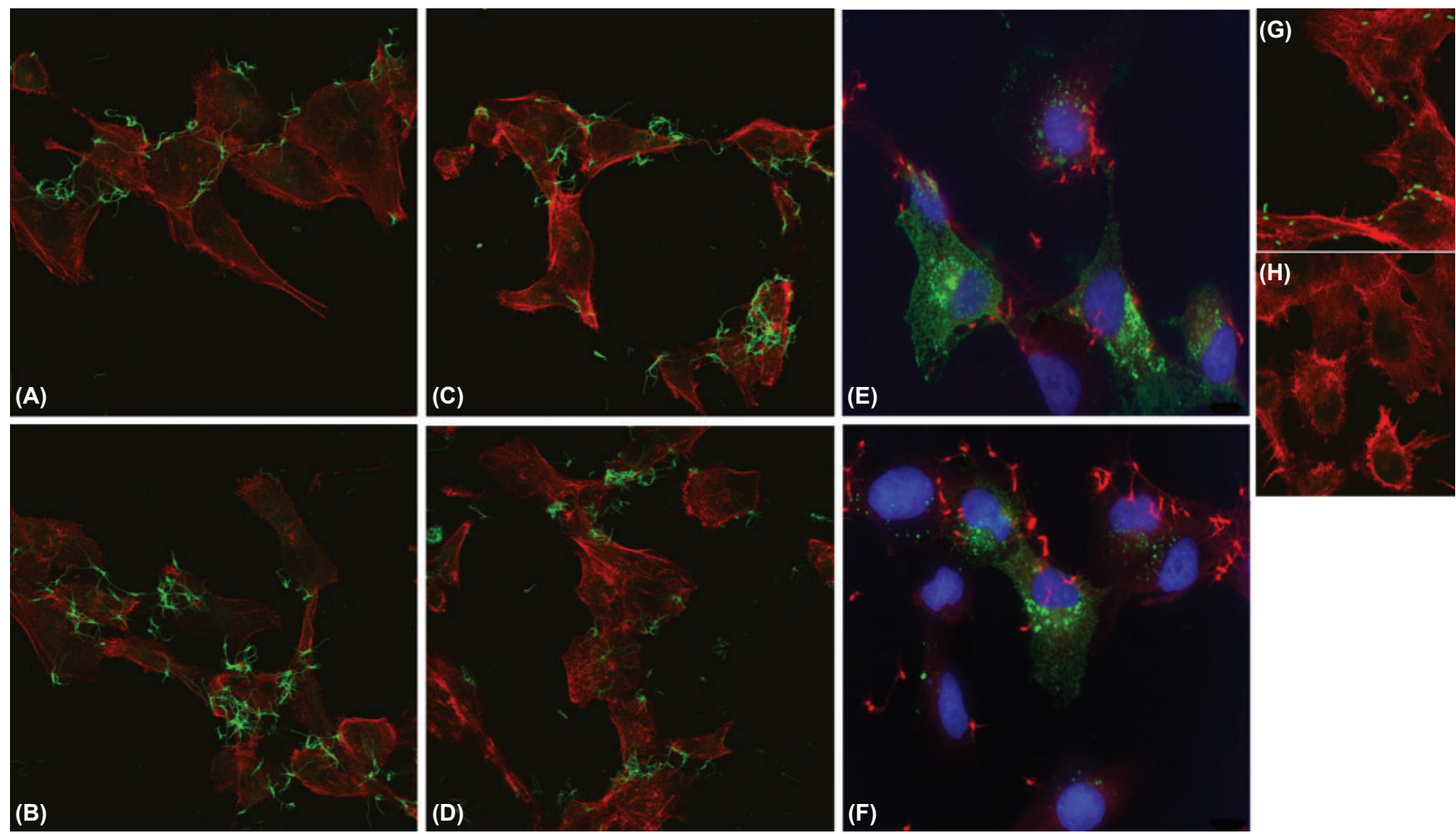

Fig. 5. Comparison of $P$. aeruginosa PAK binding to S9 and IB3-1 cells, with and without P4. Target cells were visualized by phalloidin-actin staining (red). Bound $P$. aeruginosa (PAK strain) were detected using a rabbit anti-pilin antibody and FITCconjugated anti-species antibody. Bacteria were bound only on the upper target cell surface. (A) IB3-1 cells, (B) IB3-1 cells treated with P4, (C) S9 cells, (D) S9 cells treated with P4. (E, F) Comparison of bound P. aeruginosa with anti-Gg ${ }_{4}$ staining.

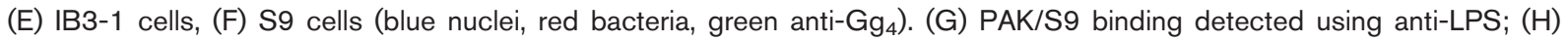
PAKnp/S9 binding detected using anti-LPS. No difference in cell binding for $P$. aeruginosa treated with either $0.5 \%$ BSA or gelatin was detected.

Strong $\mathrm{Gg}_{3}$ and $\mathrm{Gg}_{4}$ binding was seen for the cell-free T4P (Fig. 8). No binding of the T4P to an unrelated glycolipid, globotriaosylceramide $\left(\mathrm{Gb}_{3}\right)$, was observed.

\section{DISCUSSION}

\section{Glycolipids are implicated, but not proven, $P$. aeruginosa receptors}

Pulmonary $P$. aeruginosa infections are a major cause of morbidity in CF. GSL receptor binding has been implicated as the initial means of T4P-mediated bacterial host cell binding, but rigorous studies establishing this connection have yet to be reported. GSL binding is a common feature of microbial pathogenesis (Lingwood, 1992, 2000). The carbohydrate of GSLs closely apposes the membrane, and is organized in dynamic lipid rafts, which are involved in signalling and internalization, to provide a receptor option commonly selected by bacterial and viral pathogens (Rosenberger et al., 2000). Many organisms have been shown to bind to two GSLs in particular, $\mathrm{Gg}_{3}$ and $\mathrm{Gg}_{4}$, with the common GalNAc $\beta 1-4 \mathrm{Gal}$ providing the shared binding epitope (Krivan et al., 1988b; Schweizer et al., 1998; Strömberg et al., 1988). This binding specificity has been ascribed to intact Pseudomonas cells, and isolated T4P responsible for attachment and twitching motility. $\mathrm{Gg}_{4}$ receptor function has often been ascribed indirectly via inhibition by the $\mathrm{mAb}$ antiGg $g_{4}$ (Davies et al., 1999; De Bentzmann et al., 1996; Hazlett et al., 1993; Hobden et al., 1996).

\section{GSLs are not $\boldsymbol{P}$. aeruginosa receptors}

We question the $\mathrm{Gg}_{4}$ receptor function for intact organisms, as our investigation of more than $12 \mathrm{P}$. aeruginosa strains showed no evidence for GSL, let alone $\mathrm{Gg}_{3}$ or $\mathrm{Gg}_{4}$, binding by TLC overlay and, for several strains, by RELISA. The exponential-phase culture conditions used to radiolabel the organisms retain viability and T4P expression. Metabolic labelling provides the least ambiguous means to detect binding of viable organisms. RELISA using stationary-phase organisms and immunodetection supported these findings. However, some other factor involved in GSL binding may be suboptimal under our culture conditions. Irrespective of any overt or subtle GSL-binding phenotype, Pseudomonas 

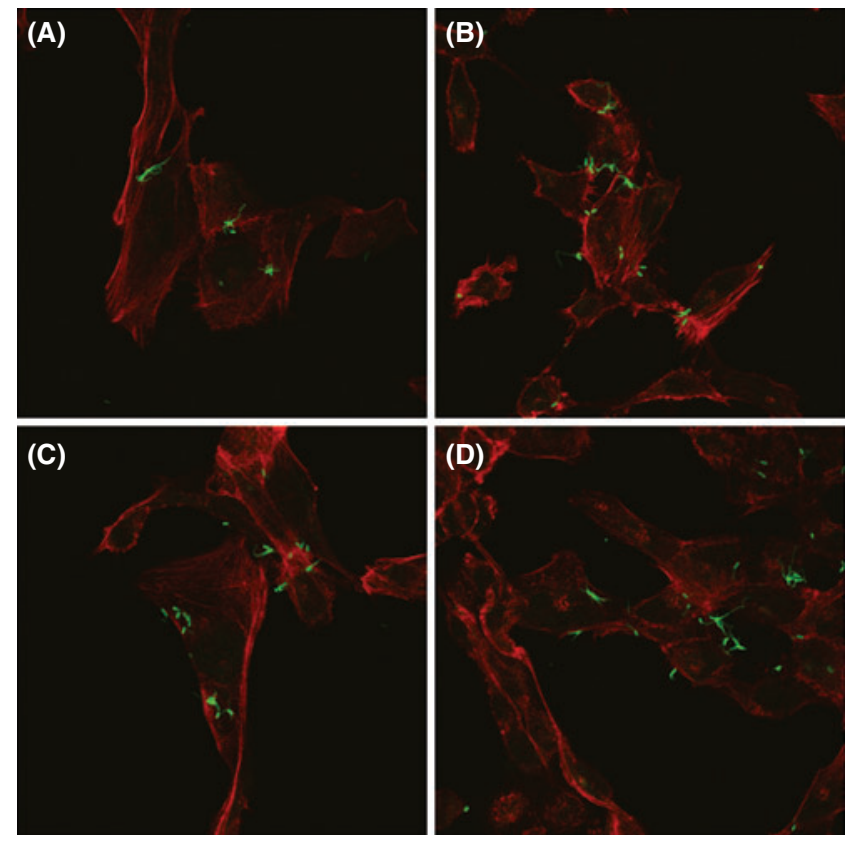

Fig. 6. Cell binding of $P$. aeruginosa pilT mutant. The binding of the hyperpiliated pilT mutant, which is unable to retract pili, to untreated and P4-treated IB3-1/S9 cells was compared. (A) Untreated IB3-1 cells, (B) P4-treated IB3-1 cells, (C) untreated S9 cells, (D) P4-treated S9 cells.

strains attach to human lung epithelial cells in an efficient manner, regardless of the presence of cell surface GSLs $\left(\mathrm{Gg}_{3}\right.$ and $\left.\mathrm{Gg}_{4}\right)$. Immunostaining with anti- $\mathrm{Gg}_{4}$ showed that $\mathrm{Gg}_{4}$ is available on the cell surface, but distinct from the sites of bacterial attachment.

\section{CF cells express more $\mathbf{G g}_{4}$}

An accumulation of $\mathrm{Gg}_{4}$ in CF cells (Bryan et al., 1998; Saiman \& Prince, 1993), resulting from hyposialylation (Poschet et al., 2001) due to an altered Golgi pH in CFTR mutant cells, has been questioned (Jiang et al., 1997), but was verified in our work. IB3-1 cells contain at least twice the levels of $\mathrm{Gg}_{4}$ of $\mathrm{S} 9$ cells; intracellular $\mathrm{Gg}_{4}$, in structures consistent with Golgi/ER, was observed for both cell types. $\mathrm{Gg}_{3}$ was barely detected in either cell line. The distinction in surface $\mathrm{Gg}_{4}$ expression, but the lack of differential $P$. aeruginosa binding to IB3-1 and S9 cells, and our finding that bacteria bind to regions of the plasma membrane devoid of anti- $\mathrm{Gg}_{4}$ binding, argue against $\mathrm{Gg}_{4}$ receptor function.

\section{GSL depletion does not affect $\boldsymbol{P}$. aeruginosa T4P-mediated binding}

It is surprising, in light of the many studies reporting $\mathrm{Gg}_{3}$ and $\mathrm{Gg}_{4}$ binding by Pseudomonas (Bryan et al., 1998; De Bentzmann et al., 1996) (or its T4P) and other bacterial

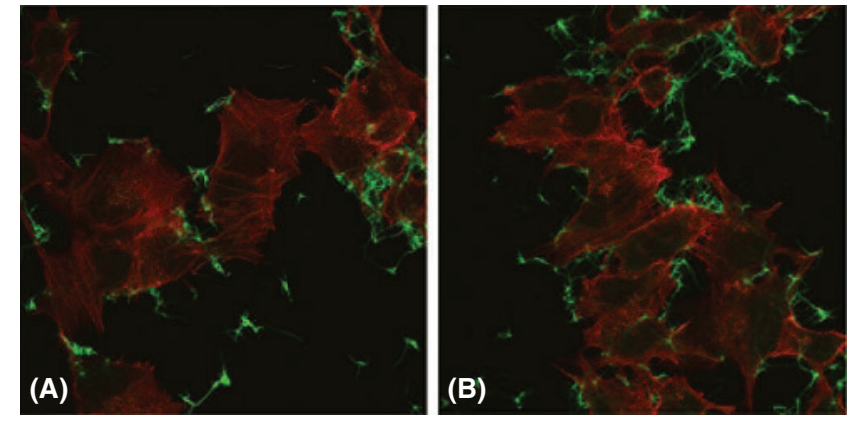

Fig. 7. Comparison of $P$. aeruginosa PAK binding BHK cells transfected with CFTR. (A) PAK-wt-CFTR-BHK cell binding, (B) PAK- $\triangle$ F508-CFTR-BHK cell binding, Bacteria binding to host-cell-bound organisms form extensive networks, irrespective of CFTR expression (or P4 treatment, not shown).

pathogens (Deal \& Krivan, 1990; Krivan et al., 1991; Strömberg et al., 1988), that the effect of depletion of cellular GSLs on bacterial binding has not been reported. Competitive inhibition of glucosylceramide synthase with a substrate analogue P4 (Lee et al., 1999), in both S9 and IB3-1 cells (and BHK cells), resulted in the loss of anti- $\mathrm{Gg}_{4}$ (not present in BHK cells), TLC and cell-surface binding, but the expression of a non-glucosylceramide-based GSL, SGC, was not affected. This attests to the efficacy and specificity of GSL inhibition. It is clear that Pseudomonas expressing $\mathrm{T} 4 \mathrm{P}$ retain the ability to bind these cell types, either with or without GSL inhibition.

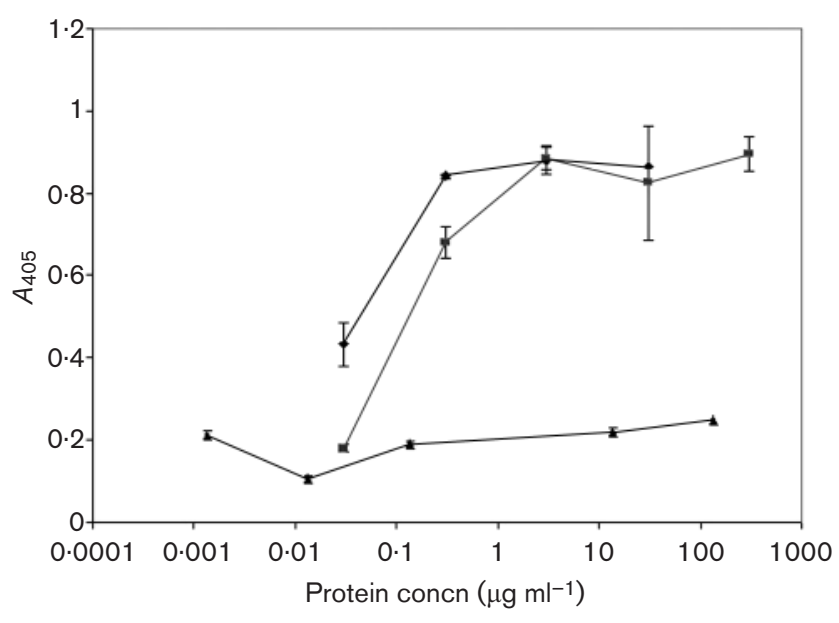

Fig. 8. GSL binding of released PAK T4P. T4P were prepared by shearing from $P$. aeruginosa $P A K$, and analysed for pilin content by SDS-PAGE and Western blotting using anti-pilin antibodies (not shown). Binding to $\mathrm{Gg}_{3}(\boldsymbol{})$ and $\mathrm{Gg}_{4}(\boldsymbol{\square})$ was monitored by RELISA, using rabbit anti-pilin antibodies. No binding to the unrelated $\mathrm{GSL} \mathrm{Gb}_{3}(\boldsymbol{\Delta})$ was observed. Error bars show SD. 
The similar binding of $P$. aeruginosa to BHK cells expressing either wt or $\triangle \mathrm{F} 508 \mathrm{CFTR}$, in which a clear difference in CFTR expression on the cell surface is seen, is also inconsistent with a receptor function for CFTR (Pier et al., 1997). Under our assay conditions, non-piliated $P$. aeruginosa mutants do not bind cells (Woods et al., 1980), despite the fact that such strains bind mucins (Ramphal et al., 1991b). O-linked mucin carbohydrates have been implicated in $P$. aeruginosa flagellum-mediated binding (Ramphal \& Arora, 2001), which may play a later role, particularly within the accumulated mucus of the $\mathrm{CF}$ airway. T4P are required for initial host cell attachment, twitching motility, and the subsequent development of a non-cell-attached biofilm (Wall \& Kaiser, 1999). Prevention of initial T4P attachment should prevent twitching and biofilm development (Burrows, 2005). Our assay conditions were adjusted to assess T4P-mediated $P$. aeruginosa initial attachment. Other adhesive mechanisms, which might occur later, could nevertheless involve GSLs.

\section{Cell-free T4P bind $\mathrm{Gg}_{3}$ and $\mathbf{G g}_{4}$}

Our finding that T4P bind both $\mathrm{Gg}_{3}$ and $\mathrm{Gg}_{4}$ when sheared from the $P$. aeruginosa organism is unlikely to result from increased sensitivity due to increased 'pilin concentration', as compared with the intact organism. Our studies show that the polyclonal anti-pilin antibody binds to the bacterium itself, and thus the bacterium would serve to amplify any signal resulting from GSL-bound pili. Our finding offers an explanation for earlier results indicating bacteria- $\mathrm{Gg}_{3} / \mathrm{Gg}_{4}$ binding (de Bentzmann et al., 1996; Hazlett et al., 1993; Krivan et al., 1988a; Ramphal et al., 1991a). If $P$. aeruginosa cultures assessed for binding contained cell-free T4P, GSL-bacteria binding could be inferred. Any pathophysiological significance of bacteriafree $\mathrm{T} 4 \mathrm{P}$ binding to $\mathrm{Gg}_{3}$ and $\mathrm{Gg}_{4}$ remains to be determined. In our cell-binding assays, it is clear that the intact bacterium is visualized bound to the eukaryotic cells using anti-pilin immunostaining. We did not observe free pili or pili fragments bound. Nevertheless if present, such binding could initiate signalling pathways (McNamara et al., 2001).

Why cell-free, but not $P$. aeruginosa-attached T4P, bind GSLs is an interesting question for future study. GSL recognition is a function of a C-terminal disulfide-linked domain at the pilus tip (Lee et al., 1994). We see that the T4P tips are clearly visible on eukaryotic-cell-attached $P$. aeruginosa, which should therefore be available for GSL binding. The finding that anti- $\mathrm{Gg}_{4}$ antibodies react with Pseudomonas LPS (Schroeder et al., 2001) may have a relevant structural basis. $\mathrm{Gg}_{4}$ is a ganglioseries GSL containing the core sequence $\mathrm{Gal} \beta 1-3 \mathrm{GalNAc} \beta 1-4 \mathrm{Gal}$. If the internal galactose is sialylated, this is the ganglioside GM1. Bacterial mimicry of the GM1 carbohydrate sequence within the LPS of Campylobacter jejuni (Aspinall et al., 1994) has been suggested to be the initiator of Guillain-Barré syndrome (Yuki et al., 1992). We considered whether $P$. aeruginosa LPS $\mathrm{O}$ antigen might contain a ' $\mathrm{Gg}_{4}$-like' sugar sequence. Bacterial-attached T4P binding to exogenous $\mathrm{Gg}_{4}$ might be prevented by binding endogenous bacterial LPS. Such inhibition might be relieved if the T4P were removed from the bacterium. We therefore tested a T4P-expressing $P$. aeruginosa mutant devoid of $\mathrm{O}$ antigen, but this also did not bind $\mathrm{Gg}_{4}$ in a RELISA (not shown). Thus, LPS is not the inhibitor of bacteria-bound $\mathrm{T} 4 \mathrm{P} / \mathrm{Gg}_{4}$ binding. We find extensive interbacterial binding of host-cell-bound $P$. aeruginosa. This is not merely aggregation but rather a 'T4P tip to T4P tip' interaction to give a network of attached bacteria. The pilus tip is the $\mathrm{Gg}_{3} / \mathrm{Gg}_{4}$ binding domain (Lee et al., 1994), and thus interpilus binding may prevent bacterial $\mathrm{Gg}_{3} / \mathrm{Gg}_{4}$ binding. A further possibility is the disassembly of the pilus subunits once detached from the bacterium, and the augmentary or differential binding of the smaller fragments, each of which contains a receptorbinding-tip domain. The identification of the inhibitory mechanism remains a matter for future study.

\section{ACKNOWLEDGEMENTS}

These studies were supported by the BREATHE program grant funded by the Canadian Cystic Fibrosis Foundation (CCCF). H.-J.P. was supported by a Sellers Foundation grant, and R. M. by the SickKids Foundation. J. K. is the recipient of a studentship from the CCFF. The authors thank Dr D. Foster, Ryerson University, for help with CL56 studies.

\section{REFERENCES}

Aspinall, G. O., McDonald, A. G., Pang, H., Kurjanczyk, L. A. \& Penner, J. L. (1994). Lipopolysaccharides of Campylobacter jejuni serotype $\mathrm{O}: 19$ : structures of core oligosaccharide regions from the serostrain and two bacterial isolates from patients with the GuillainBarre syndrome. Biochemistry 33, 241-249.

Baker, N., Hansson, G. C., Leffler, H., Riise, G. \& Svanborg-Edën, C. (1990). Glycosphingolipid receptors for Pseudomonas aeruginosa. Infect Immun 58, 2361-2366.

Barnett-Foster, D. E., Philpott, D., Abul-Milh, M., Huesca, M., Sherman, P. M. \& Lingwood, C. A. (1999). Phosphatidylethanolamine recognition mediates enteropathogenic and enterohemorrhagic E. coli host cell attachment. Microb Pathog 27, 289-301.

Bryan, R., Kube, D., Perez, A., Davis, P. \& Prince, A. (1998). Overproduction of the CFTR R domain leads to increased levels of asialoGM1 and increased Pseudomonas aeruginosa binding by epithelial cells. Am J Respir Cell Mol Biol 19, 269-277.

Burrows, L. L. (2005). Weapons of mass retraction. Mol Microbiol 57, 878-888.

Campbell, A. P., Wong, W. Y., Houston, M., Jr, Schweizer, F., Cachia, P. J., Irvin, R. T., Hindsgaul, O., Hodges, R. S. \& Sykes, B. D. (1997). Interaction of the receptor binding domains of Pseudomonas aeruginosa pili strains $\mathrm{PAK}, \mathrm{PAO}, \mathrm{KB} 7$ and $\mathrm{P} 1$ to a cross-reactive antibody and receptor analog: implications for synthetic vaccine design. J Mol Biol 267, 382-402.

Chen, L. D. \& Hazlett, L. D. (2000). Perlecan in the basement membrane of corneal epithelium serves as a site for $P$. aeruginosa binding. Curr Eye Res 20, 260-267.

Chiang, P. \& Burrows, L. L. (2003). Biofilm formation by hyperpiliated mutants of Pseudomonas aeruginosa. J Bacteriol 185, 2374-2378. 
Comolli, J. C., Hauser, A. R., Waite, L., Whitchurch, C. B., Mattick, J. S. \& Engel, J. N. (1999a). Pseudomonas aeruginosa gene products PilT and PilU are required for cytotoxicity in vitro and virulence in a mouse model of acute pneumonia. Infect Immun 67, $3625-3630$.

Comolli, J. C., Waite, L. L., Mostov, K. E. \& Engel, J. N. (1999b). Pili binding to asialo-GM1 on epithelial cells can mediate cytotoxicity or bacterial internalization by Pseudomonas aeruginosa. Infect Immun 67, 3207-3214.

Davies, J. C. (2002). Pseudomonas aeruginosa in cystic fibrosis: pathogenesis and persistence. Paediatr Respir Rev 3, 128-134.

Davies, J., Dewar, A., Bush, A., Pitt, T., Gruenert, D., Geddes, D. M. \& Alton, E. W. (1999). Reduction in the adherence of Pseudomonas aeruginosa to native cystic fibrosis epithelium with anti-asialoGM1 antibody and neuraminidase inhibition. Eur Respir J 13, 565-570.

Deal, C. \& Krivan, H. C. (1990). Lacto- and ganglio-series glycolipids are adhesion receptors for Neisseria gonorrhoeae. J Biol Chem 265, 12774-12777.

De Bentzmann, S., Roger, P., Dupuit, F., Bajolet-Laudinat, O., Fuchey, C., Plotkowski, M. C. \& Puchelle, E. (1996). Asialo GM1 is a receptor for Pseudomonas aeruginosa adherence to regenerating respiratory epithelial cells. Infect Immun 64, 1582-1588.

de Bentzmann, S., Roger, P. \& Puchelle, E. (1996). Pseudomonas aeruginosa adherence to remodelling respiratory epithelium. Eur Respir J 9, 2145-2150.

Gibson, R. L., Burns, J. L. \& Ramsey, B. W. (2003). Pathophysiology and management of pulmonary infections in cystic fibrosis. Am J Respir Crit Care Med 168, 918-951.

Gupta, S. K., Berk, R. S., Masinick, S. \& Hazlett, L. D. (1994). Pili and lipopolysaccharide of Pseudomonas aeruginosa bind to the glycolipid asialo GM1. Infect Immun 62, 4572-4579.

Haardt, M., Benharouga, M., Lechardeur, D., Kartner, N. \& Lukacs, G. L. (1999). C-terminal truncations destabilize the cystic fibrosis transmembrane conductance regulator without impairing its biogenesis. A novel class of mutation. J Biol Chem 274, 21873-21877.

Hazlett, L. D., Masinick, S., Barrett, R. \& Rosol, K. (1993). Evidence for asialo GM1 as a corneal glycolipid receptor for Pseudomonas aeruginosa adhesion. Infect Immun 61, 5164-5173.

Hobden, J. A., Gupta, S. K., Masinick, S. A., Wu, X., Kernacki, K. A., Berk, R. S. \& Hazlett, L. D. (1996). Anti-receptor antibodies inhibit Pseudomonas aeruginosa binding to the cornea and prevent corneal perforation. Immunol Cell Biol 74, 258-264.

Irvin, R. T., Doig, P., Lee, K. K., Sastry, P. A., Paranchych, W., Todd, T. \& Hodges, R. S. (1989). Characterization of the Pseudomonas aeruginosa pilus adhesion: confirmation that the pilin structural protein subunit contains a human epithelial cell-binding domain. Infect Immun 57, 3720-3726.

Jiang, X., Hill, W. G., Pilewski, J. M. \& Weisz, O. A. (1997). Glycosylation differences between a cystic fibrosis and rescued airway cell line are not CFTR dependent. Am J Physiol 273, L913-920.

Kirschnek, S., Adams, C. \& Gulbins, E. (2005). Annexin II is a novel receptor for Pseudomonas aeruginosa. Biochem Biophys Res Commun 327, 900-906.

Krivan, H. C., Ginsburg, V. \& Roberts, D. D. (1988a). Pseudomonas aeruginosa and Pseudomonas cepacia isolated from cystic fibrosis patients bind specifically to gangliotetraosylceramide (asialo GM1) and gangliotriaosylceramide (asialo GM2). Arch Biochem Biophys 260, 493-496.

Krivan, H. C., Roberts, D. D. \& Ginsburg, V. (1988b). Many pulmonary pathogenic bacteria bind specifically to the carbohydrate sequence GalNAc $\beta 1-4$ Gal found in some glycolipids. Proc Natl Acad Sci U S A 85, 6157-6161.
Krivan, H., Nilsson, B., Lingwood, C. A. \& Ryu, H. (1991). Chlamydia trachomatis and Chlamydia pneumoniae bind specifically to phosphatidylethanolamine in HeLa cells and to GalNac $\beta 1-4 \mathrm{Gal} \beta 1-4 \mathrm{Glc}$ sequences found in asialo-GM1 and asialo-GM2. Biochem Biophys Res Commun 175, 1082-1089.

Kus, J. V., Tullis, E., Cvitkovitch, D. G. \& Burrows, L. L. (2004). Significant differences in type IV pilin allele distribution among Pseudomonas aeruginosa isolates from cystic fibrosis (CF) versus non-CF patients. Microbiology 150, 1315-1326.

Lee, K., Sheth, H., Wong, W., Serburne, R., Paranchych, W., Hodges, R. C. L., Krivan, H. \& Irvin, R. (1994). The binding of Pseudomonas aeruginosa pili to glycosphingolipids is a tip associated event involving the C-terminal region of the structural pilin subunit. Mol Microbiol 11, 705-713.

Lee, K. K., Yu, L., Macdonald, D. L., Paranchych, W., Hodges, R. S. \& Irvin, R. T. (1996). Anti-adhesin antibodies that recognize a receptorbinding motif (adhesintope) inhibit pilus/fimbrial-mediated adherence of Pseudomonas aeruginosa and Candida albicans to asialo- $\mathrm{GM}_{1}$ receptors and human buccal epithelial cell surface receptors. Can J Microbiol 42, 479-486.

Lee, L., Abe, A. \& Shayman, J. A. (1999). Improved inhibitors of glucosylceramide synthase. J Biol Chem 274, 14662-14669.

Lingwood, C. A. (1992). Bacterial cell adhesins/glycolipid receptors. Curr Opin Struct Biol 2, 693-700.

Lingwood, C. A. (2000). Glycolipids and bacterial pathogenesis. In Oligosaccharides in Chemistry and Biology: a Comprehensive Handbook, pp. 809-820. Edited by B. Ernst, P. Sinay \& G. Hart. Wenheim: Wiley-VCH.

McNamara, N., Khong, A., McKemy, D., Caterina, M., Boyer, J., Julius, D. \& Basbaum, C. (2001). ATP transduces signals from ASGM1, a glycolipid that functions as a bacterial receptor. Proc Natl Acad Sci U S A 98, 9086-9091.

Pier, G. B., Grout, M. \& Zaidi, T. S. (1997). Cystic fibrosis transmembrane conductance regulator is an epithelial cell receptor for clearance of Pseudomonas aeruginosa from the lung. Proc Natl Acad Sci U S A 94, 12088-12093.

Poschet, J. F., Boucher, J. C., Tatterson, L., Skidmore, J., Van Dyke, R. W. \& Deretic, V. (2001). Molecular basis for defective glycosylation and Pseudomonas pathogenesis in cystic fibrosis lung. Proc Natl Acad Sci U S A 98, 13972-13977.

Ramphal, R. \& Arora, S. K. (2001). Recognition of mucin components by Pseudomonas aeruginosa. Glycoconj J 18, 709-713.

Ramphal, R., Carnoy, C., Fievre, S., Michalski, J.-C., Houdret, N., Lamblin, G., Strecker, G. \& Roussel, P. (1991a). Pseudomonas aeruginosa recognizes carbohydrate chains containing type 1 (Gal/1$3 \mathrm{GlcNAc}$ ) or type 2 (Gal $\beta 1-4 \mathrm{GlcNAc})$ diaccharide units. Infect Immun 59, 700-704.

Ramphal, R., Koo, L., Ishimoto, K. S., Totten, P. A., Lara, J. C. \& Lory, S. (1991b). Adhesion of Pseudomonas aeruginosa pilin-deficient mutants to mucin. Infect Immun 59, 1307-1311.

Rosenberger, C. M., Brumell, J. H. \& Finlay, B. B. (2000). Microbial pathogenesis: lipid rafts as pathogen portals. Curr Biol 10, R823-825.

Saiman, L. \& Prince, A. (1993). Pseudomonas aeruginosa pili bind to asialoGM1 which is increased on the surface of cystic fibrosis epithelial cells. J Clin Invest 92, 1875-1880.

Schroeder, T. H., Zaidi, T. \& Pier, G. B. (2001). Lack of adherence of clinical isolates of Pseudomonas aeruginosa to asialo-GM(1) on epithelial cells. Infect Immun 69, 719-729.

Schweizer, F., Jiao, H., Hindsgaul, O., Wong, W. Y. \& Irvin, R. T. (1998). Interaction between the pili of Pseudomonas aeruginosa PAK and its carbohydrate receptor $\beta$-D-GalNAc $(1 \rightarrow 4) \quad \beta$-D-Gal analogs. Can J Microbiol 44, 307-311. 
Sharma, M., Pampinella, F., Nemes, C. \& 8 other authors (2004). Misfolding diverts CFTR from recycling to degradation: quality control at early endosomes. J Cell Biol 164, 923-933.

Strömberg, N., Deal, C., Nyberg, G., Normark, S., So, M. \& Karlsson, K.-A. (1988). Identification of carbohydrate structures that are possible receptors for Neisseria gonorrhoeae. Proc Natl Acad Sci U S A 85, 4902-4906.

Virella-Lowell, I., Herlihy, J. D., Liu, B., Lopez, C., Cruz, P., Muller, C., Baker, H. V. \& Flotte, T. R. (2004). Effects of CFTR, interleukin-10, and Pseudomonas aeruginosa on gene expression profiles in a $\mathrm{CF}$ bronchial epithelial cell Line. Mol Ther 10, 562-573.

Wall, D. \& Kaiser, D. (1999). Type IV pili and cell motility. Mol Microbiol 32, 1-10.

Woods, D. E., Straus, D. C., Johanson, W. G., Jr, Berry, V. K. \& Bass, J. A. (1980). Role of pili in adherence of Pseudomonas aeruginosa to mammalian buccal epithelial cells. Infect Immun 29, 1146-1151.
Wu, X., Gupta, S. K. \& Hazlett, L. D. (1995). Characterization of $P$. aeruginosa pili binding human corneal epithelial proteins. Curr Eye Res 14, 969-977.

Wu, X., Kurpakus, M. \& Hazlett, L. D. (1996). Some P. aeruginosa pilus-binding proteins of human corneal epithelium are cytokeratins. Curr Eye Res 15, 782-791.

Yiu, S. C. K. \& Lingwood, C. A. (1992). Polyisobutylmethacrylate modifies glycolipid binding specificity of verotoxin 1 in thin layer chromatogram overlay procedures. Anal Biochem 202, 188-192.

Yuki, N., Handa, S., Taki, T., Kasama, T., Takahashi, M., Saito, K. \& Miyataki, T. (1992). Cross-reactive antigen between nervous tissue and a bacterium elicits Guillain-Barre syndrome: molecular mimicry between ganglioside GM1 and lipopolysaccahride from Penner's serotype 19 of Campylobacter jejuni. Biomed Res 13, 451-453. 